\title{
Extended Release Bupivacaine Hydrochloride Resorbable Matrix Formulation
}

National Cancer Institute

\section{Source}

National Cancer Institute. Extended Release Bupivacaine Hydrochloride Resorbable

Matrix Formulation. NCI Thesaurus. Code C102745.

An extended release (ER) injectable formulation composed of the hydrochloride salt form of bupivacaine, an amide-type, long-acting local anesthetic, in a resorbable sucrose acetate isobutyrate-based matrix, with analgesic activity. Following administration in or around a specific site, ER bupivacaine is released from the matrix over an extended period of time. Upon release, bupivacaine reversibly binds to specific voltage-gated sodium ion channels in the neuronal membrane, resulting in a decrease in the voltagedependent membrane permeability to sodium ions, membrane destabilization, and depolarization inhibition thus disrupting nerve impulse conduction. This eventually leads to a reversible loss of sensation. This formulation may provide pain relief up to 72 hours. 